\title{
Teores foliares de macronutrientes em quiabeiro cultivado sob diferentes fontes e níveis de matéria orgânica
}

\section{Macronutrient contents in okra plants under different sources and levels of organic matter on soil}

\author{
Lourival Ferreira Cavalcante ${ }^{1 *}$; Adriana Araujo Diniz ${ }^{2}$; \\ Luís Carlos Francisco dos Santos ${ }^{3}$; Alex Matheus Rebequi ${ }^{4}$; \\ Járisson Cavalcante Nunes ${ }^{5}$; Míriam Alice da Silva Brehm ${ }^{4}$
}

\section{Resumo}

Um experimento foi conduzido no período de novembro de 2001 a abril de 2002, com o objetivo de avaliar os efeitos de fontes e níveis de matéria orgânica sobre os teores foliares de macronutrientes em quiabeiro 'Santa Cruz'. O delineamento experimental utilizado foi em blocos casualizados, em esquema fatorial, com quatro repetições, com duas plantas por cova e 25 plantas por parcela. Foram utilizadas três fontes de matéria orgânica: esterco bovino, esterco de frango e esterco de caprino, fornecidos em quatro níveis: $0,5,10$ e $15 \%$ do volume da cova com capacidade para 48 litros. O esterco de frango proporcionou maiores teores de cálcio, fósforo e magnésio, o esterco de caprino maior de potássio e o esterco de bovino maiores valores de nitrogênio nas folhas das plantas de quiabeiro, mas sem definição estatística de doses entre as distintas fontes de matéria orgânica.

Palavras-chave: Adubação orgânica, composição foliar, Abelmoschus esculentus

\begin{abstract}
An experiment was carried out during the period of November of 2001 to April of 2002 in order to evaluate the effects of sources and doses of organic matter on leaf mineral composition of okra cv. Santa Cruz. The treatments were distributed in a randomized blocks design with four replications with 25 holes with two plants in each plot. The treatments were arranged in a $3 \times 4$ factorial design, with three sources of organic matter: cattle manure, chicken manure and caprine manure incorporated at soil in four levels in volume of: $0.0 ; 5.0 ; 10.0$ and $15.0 \%$ of the hole (capacity for 48 liters). Okra plants treated with chicken manure had higher foliar content of calcium, magnesium and phosphorus; with the goat manure the higher content of potassium, and with bovine manure higher values of nitrogen in leaf dry matter of plants, but with no difference among doses of manure.
\end{abstract}

Key words: Organic fertilization, leaf mineral composition, Abelmoschus esculentus

\footnotetext{
1 Professor Adjunto do Departamento de Solos e Engenharia Rural, CCA/UFPB - Universidade Federal de Paraíba, Areia-PB. E-mail: lofeca@cca.ufpb.br

2 Eng. Agr., Dr. em Agronomia, CCA/UFPB - Universidade Federal de Paraíba, Areia-PB. E-mail: adrisolos@bol.com.br

3 Engenheiro Agrônomo, CCA/UFPB. Areia-PB. E-mail: santoslcf@yahoo.com.br

4 Respectivamente Estudantes do PPGMSA,CCA/UFPB-Universidade Federal de Paraíba,Areia-Paraíba.E-mail: alexrebequi@, hotmail.com; miriambrehm@yahoo.com.br

5 Estudante de Graduação em Agronomia, CCA/UFPB - Universidade Federal de Paraíba, Areia - Paraíba. E-mail: jarissonagro@ hotmail.com

* Autor para correspondência
} 


\section{Introdução}

O Brasil caracteriza-se como um país de adequadas condições para o cultivo da grande maioria das plantas cultivadas de interesse econômico, inclusive, o quiabeiro que é considerado uma planta rústica, tolerante ao calor e não exige tecnologia muito avançada para seu cultivo, sendo mais explorado nas regiões Nordeste e Sudeste (OLIVEIRA et al, 2003; MOTA et al., 2005) e pode ser produzido durante o ano todo, em regiões de clima quente (OLIVEIRA et al, 2007a).

Em função da crescente preferência pelo consumidor, tem-se registrado expressiva expansão da cultura do quiabeiro em todo o Brasil, principalmente nos Estados do Rio de Janeiro, São Paulo e Sergipe. No estado de São Paulo do inicio ao final da década de 90 a área cultivada com essa olerícola aumentou de 621 para 1575 hectares. Aumentos significativos foram também registrados no Brasil Central, Rio de Janeiro, Sergipe, Paraíba e Pernambuco (SANTOS, 2002; SANTOS et al., 2005; OLIVEIRA et al., 2007b).

Atualmente as novas tecnologias de produção presentes no mercado acarretam riscos cada vez maiores, aumentando a escala, a freqüência e o impacto de desastres causados ou influenciados pela atividade humana (RODOLFO JÚNIOR; CAVALCANTE; BURITI, 2008). Assim, uma redução na aplicação de fertilizantes comerciais pode prevenir problemas ecológicos causados pela aplicação excessiva desses insumos ao solo (YUKUI et al., 2009).

Em termos nutricionais, uma alternativa viável pode ser a substituição de fertilizantes minerais por insumos orgânicos de origem vegetal e animal. Esses produtos, em geral são de preços mais acessíveis e influenciam positivamente nas propriedades físicas, químicas e biológicas do solo além de agredirem menos o meio ambiente (PIRES et al., 2008).

A nutrição mineral equilibrada das plantas, inclusive as olerícolas pode influenciar no desenvolvimento vegetal e na qualidade da produção obtida (MOTA et al., 2008). Para os autores, a adubação orgânica pode ser feita ao nível de 40 a 60 t ha ${ }^{-1}$ de esterco bovino. A adubação de cobertura de acordo com o potencial de fertilidade do solo deve ser fornecida aos 20, 40 e 60 dias após a emergência das plântulas ou após o transplantio das mudas (NAGAI, 1998).

A nutrição mineral do quiabeiro caracteriza-se por uma extração de macros e micronutrientes lenta até os 20 dias, vindo a aumentar posteriormente. Os teores de nutrientes nas folhas de plantas de quiabo sob deficiência nutricional determinados aos 60 dias foram próximos de 18,2 $\mathrm{g} \mathrm{kg}^{-1}$ de $\mathrm{N} ; 1,7 \mathrm{~g} \mathrm{~kg}^{-1}$ de P; $10,5 \mathrm{~g} \mathrm{~kg}^{-1}$ de K; 29,4 $\mathrm{g} \mathrm{kg}^{-1}$ de Ca e 2,4 $\mathrm{g} \mathrm{kg}^{-1}$ de $\mathrm{Mg}$, enquanto os desenvolvidos sem deficiências minerais foram $37,1 \mathrm{~g} \mathrm{~kg}^{-1}$ de $\mathrm{N} ; 4,1 \mathrm{~g} \mathrm{~kg}^{-1}$ de $\mathrm{P} ; 20$ $\mathrm{g} \mathrm{kg}^{-1}$ de $\mathrm{K} ; 37,3 \mathrm{~g} \mathrm{~kg}^{-1}$ de $\mathrm{Ca}$ e 8,6 $\mathrm{g} \mathrm{kg}^{-1}$ de $\mathrm{Mg}$ (COSTA; HAAG; SARRUGE, 1972).

Berbara, Freire e Fernandes (1999) ao avaliarem a influência da colonização micorrízica arbuscular sobre a nutrição do quiabeiro observaram que seus resultados indicaram resposta positiva do quiabeiro ao $\mathrm{P}$, com valores de matéria seca e área radicular das plantas em geral, superiores nos tratamentos com $60 \mathrm{~kg} \mathrm{ha}^{-1}$ de P. Filgueira (2008) acrescenta que a cultura responde bem a aplicações de $\mathrm{P}$ e $\mathrm{N}$, bem como responde à adubação orgânica.

Ao considerar a qualidade nutricional do fruto do quiabo, a preferência da população por alimentos de boa qualidade, a exigência mundial de se produzir alimentos e produtos usando cada vez menos insumos sintetizados, é que o aumento da agricultura alternativa baseada na agroecologia cresce em ritmo acelerado; e ao considerar também a carência de informações sobre a nutrição mineral do quiabeiro na literatura brasileira, a realização de trabalhos dessa natureza deve ser mais frequentemente desenvolvida.

O trabalho teve como objetivo avaliar os efeitos de fontes e níveis de matéria orgânica sobre os teores foliares de macronutrientes em quiabeiro 'Santa Cruz'. 


\section{Material e métodos}

O trabalho foi desenvolvido no período de novembro/2001 a abril/2002, na propriedade Sítio Macaquinho situado a $8 \mathrm{~km}$ ao Sul da cidade de Remígio, PB. O clima do município é quente e úmido; as variáveis climáticas no local do ensaio durante o ano de 2001 foram: temperatura do ar 25 ${ }^{\circ} \mathrm{C}$, do solo protegido com cobertura morta $28{ }^{\circ} \mathrm{C}$ e descoberto $38{ }^{\circ} \mathrm{C}$, umidade relativa do ar $80 \%$ e pluviosidade $870 \mathrm{~mm}$ (SANTOS, 2001). O solo foi classificado como Cambissolo Húmico Eutrófico (SANTOS et al., 2006). Nos primeiros $40 \mathrm{~cm}$ de profundidade apresenta 834; 124; 42 e $25 \mathrm{~g} \mathrm{~kg}^{-1}$ de areia, silte, argila total e argila dispersa em água, densidade do solo e de partículas: 1,40 e 2,68 g $\mathrm{cm}^{-3}$, respectivamente, com porosidade total de 0,48 $\mathrm{m}^{3} \mathrm{~m}^{-3}$, grau de floculação e índice de dispersão de 41 e $59 \%$, respectivamente. O teor de água disponível, a umidade na tensão de $-0,01 \mathrm{MPa}$ e de $-1,5 \mathrm{MPa} 76,105$ e $29 \mathrm{~g} \mathrm{~kg}^{-1}$, respectivamente. Quanto à caracterização química, o solo na mesma profundidade possuía: $\mathrm{pH}=6,2$; $\mathrm{P}$ e $\mathrm{K}=9$ e $47 \mathrm{mg}$ $\mathrm{dm}^{-3} ; \mathrm{Na}=0,03 ; \mathrm{Ca}^{2+}=1,4 ; \mathrm{Mg}^{2+}=1,2 ; \mathrm{Al}^{2+}=0,1$, $\mathrm{H}^{+}=0,9$ e CTC $=3 \mathrm{cmol}_{\mathrm{c}} \mathrm{dm}^{-3}$, respectivamente; saturação por bases $-\mathrm{V}=72 \%$ e $\mathrm{MO}=11 \mathrm{~g} \mathrm{dm}^{-3}$, obtidos empregando as metodologias sugeridas por EMBRAPA (1997).

O plantio da cultivar Santa Cruz 47, foi feito nas distâncias de 5 metros entre linhas e 2 metros entre plantas, em cultivo intercalado com a cultura da goiabeira Paluma (Psidium guajava L), com três meses, implantada no espaçamento de 5 x 5 m. O delineamento experimental utilizado foi em blocos casualizados, em esquema fatorial, com quatro repetições, com duas plantas por cava e 25 plantas por parcela. Foram utilizadas três fontes de matéria orgânica: esterco bovino, esterco de frango e esterco de caprino fornecidas em quatro níveis: $0,5,10$ e $15 \%$ do volume da cova. As fontes de matéria orgânica possuíam a composição química indicada na Tabela 1 e a incorporação ao solo foi feita em covas com capacidade para 48 litros, isto é, de dimensões $40 \times 40 \times 30 \mathrm{~cm}$ com base na expressão: \% = 100 (volume de matéria orgânica/ volume da cova).

A partir dos valores de matéria orgânica e dos conteúdos de água existentes entre as fontes foram quantificados os volumes de cada respectiva fonte e dose a serem aplicadas ao solo, de forma a se fornecer a mesma quantidade de matéria orgânica entre as distintas fontes (Tabela 2).

Tabela 1. Caracterização química das fontes de matéria orgânica.

\begin{tabular}{|c|c|c|c|c|c|c|c|c|c|}
\hline & $\mathrm{C}$ & M.O. & $\mathrm{U}$ & $\mathrm{N}$ & $\mathrm{P}$ & $\mathrm{K}$ & $\mathrm{Ca}$ & $\mathrm{Mg}$ & $\mathrm{C} / \mathrm{N}$ \\
\hline Fonte & \multicolumn{3}{|c|}{---- $\mathrm{g} \mathrm{dm}^{-3}----$} & \multicolumn{6}{|c|}{ 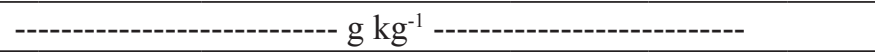 } \\
\hline Esterco bovino & 266 & 459 & 1164 & 13,7 & 4,0 & 26,2 & 10,3 & 13,1 & $19: 1$ \\
\hline Esterco de frango & 265 & 457 & 459 & 18,2 & 11,2 & 18,3 & 21,2 & 9,5 & $15: 1$ \\
\hline Esterco caprino & 298 & 514 & 100 & 10,7 & 1,9 & 20 & 11 & 14,4 & $28: 1$ \\
\hline
\end{tabular}

$\mathrm{C}=$ Carbono orgânico; M.O. = Matéria orgânica; $\mathrm{U}=$ Umidade em peso; $\mathrm{C} / \mathrm{N}=$ Relação carbono/nitrogênio 
Tabela 2. Volumes de cada fonte de matéria orgânica aplicados às covas.

\begin{tabular}{|c|c|c|c|}
\hline Matéria orgânica & F1 & F2 & F3 \\
\hline$\%$ & \multicolumn{3}{|c|}{------------------ L 48 L'-1 ---------------- } \\
\hline 0 & 0,00 & 0,00 & 0,00 \\
\hline 5 & 5,20 & 3,50 & 4,30 \\
\hline 10 & 10,40 & 7,00 & 8,60 \\
\hline 15 & 15,60 & 10,50 & 12,90 \\
\hline Umidade $\left(\mathrm{g} \mathrm{dm}^{-3}\right)$ & 1164 & 459 & 100 \\
\hline Fator para o carbono orgânico & $\mathrm{F} 1 / \mathrm{F} 1$ & $\mathrm{~F} 1 / \mathrm{F} 2$ & $\mathrm{~F} 1 / \mathrm{F} 3$ \\
\hline & 1,00 & 1,00 & 0,89 \\
\hline
\end{tabular}

$\mathrm{F} 1$ = Esterco bovino; F2 = Esterco de frango; F3 = Esterco de caprino.

A adubação de formação e produção da cultura foi feita em função da análise do solo aos trinta e sessenta dias após o transplantio. O nitrogênio foi fornecido na dose mínima de $5 \mathrm{~g} \mathrm{cova}^{-1}$ oriundo do sulfato de amônio, e o potássio, na forma de $\mathrm{KCl}$ ao nível de $10 \mathrm{~g}$ de $\mathrm{K}_{2} \mathrm{O}$ nas respectivas idades das plantas.

O suprimento hídrico das plantas foi feito com base na evaporação de tanque classe " $A$ " do dia anterior, fornecendo-se manualmente a lâmina de água evapotranspirada por cova. Para redução das perdas hídricas, durante o período da estiagem, as covas foram protegidas, da ação direta dos raios solares com cobertura de restos de culturas desidratadas, na espessura de $5 \mathrm{~cm}$ como procedeu Santos (2001) para o cultivo da pinheira irrigada.

No início da floração, foi colhida a terceira folha de cada planta para determinação dos teores de N, $\mathrm{P}, \mathrm{K}, \mathrm{Ca}$ e $\mathrm{Mg}$ na matéria seca para avaliação do estado nutricional da cultura (FILGUEIRA, 2000), adotando as metodologias contidas em Malavolta, Vitti e Oliveira (1997) e os resultados foram submetidos à análise de variância pelo teste " $F$ " e por regressão polinomial (FERREIRA, 2000).

\section{Resultados e discussão}

Os teores de N, P, K, Ca e Mg na matéria seca das folhas do quiabeiro no início da floração das plantas foram influenciados pela interação fontes $\mathrm{x}$ níveis de matéria orgânica aplicadas ao solo. Os teores de nitrogênio nos tratamentos com esterco bovino aumentaram até a maior dose de 8,4\% referente ao maior teor de 53,82 $\mathrm{g} \mathrm{kg}^{-1}$. Por outro lado, os valores de $\mathrm{N}$ decresceram com o aumento dos níveis do esterco caprino (Figura 1), devido sua composição em carbono ser superior a de nitrogênio. Situação semelhante ao esterco de bovino foi verificada para o esterco de frango em que o aumento dos respectivos insumos no solo elevou os teores foliares de nitrogênio nas plantas.

Verifica-se também na referida figura superioridade do esterco de frango em proporcionar maior acumulação de $\mathrm{N}$ nas folhas do quiabeiro em relação ao esterco de bovino e de caprino respectivamente. Essa situação expressa maior disponibilização de nitrogênio pelo esterco de frango às plantas, devido ser mais rico no nutriente que as demais fontes, conforme indicado na (Tabela 1). Ao comparar os resultados com os obtidos por Costa, Haag e Sarruge (1972) ao avaliarem a absorção de macro e micronutrientes pelo quiabeiro, foram obtidos os valores de 18,2 e $37,1 \mathrm{~g} \mathrm{~kg}^{-1}$ de $\mathrm{N}$ em plantas mantidas sob deficiência e em condições adequadamente supridas. Em ambos os casos os teores foram inferiores aos obtidos no presente estudo.

Os teores de fósforo (Figura 2) apresentaram comportamentos diferenciados entre os tratamentos sem e com os distintos níveis e fontes de matéria 
orgânica. Dentre as fontes a que proporcionou maior incremento do nutriente na matéria seca foliar das plantas foi o esterco de bovino na dose máxima estimada de $7,61 \%$ atingindo o maior valor acumulado de $13,64 \mathrm{~g} \mathrm{~kg}^{-1}$. Nos tratamentos com o esterco de frango os teores aumentaram até o maior valor de $8,15 \mathrm{~g} \mathrm{~kg}^{-1}$ para a dose de $5,10 \%$. Essa superioridade é resposta do maior teor do nutriente no respectivo insumo, em relação às demais fontes como se verifica na (Tabela1).

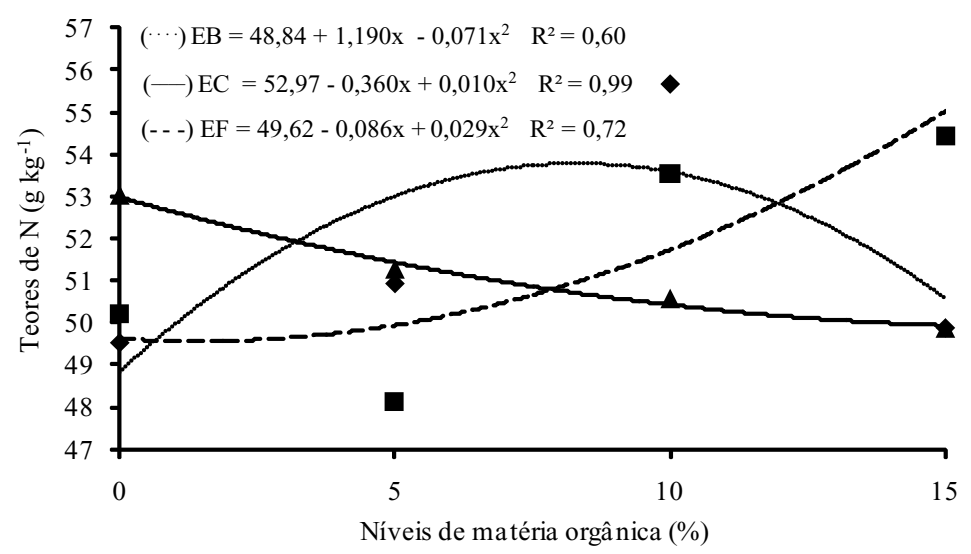

Figura 1. Teores de nitrogênio na matéria seca das folhas do quiabeiro em função de fontes e níveis de matéria orgânica incorporadas ao solo: $\mathrm{EB}=$ esterco bovino ( (…..); EF = Esterco de frango (- - ) ; EC = Esterco caprino (-)

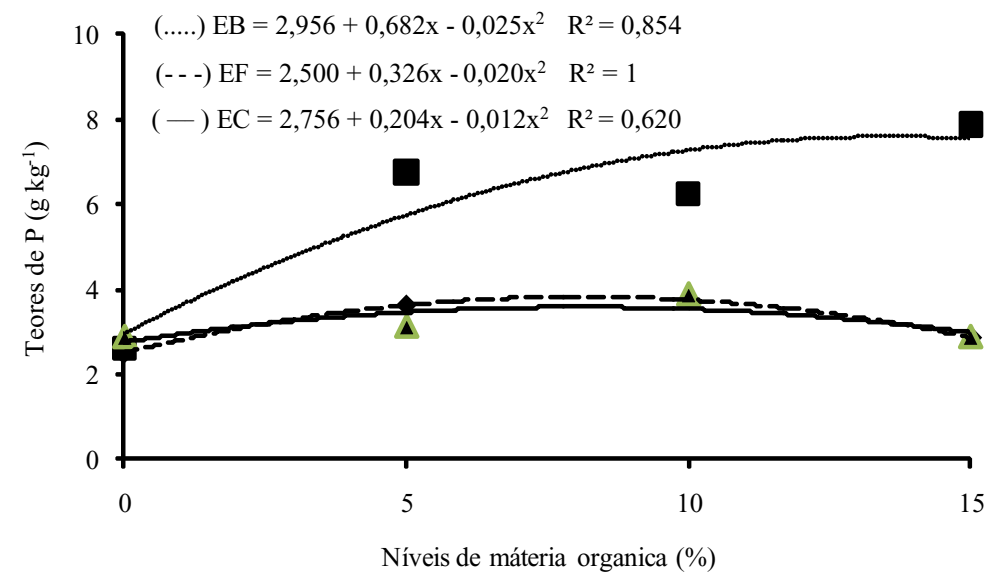

Figura 2. Teores de fósforo na matéria seca das folhas do quiabeiro em função de fontes e níveis de matéria orgânica incorporadas ao solo: $\mathrm{EB}=$ Esterco bovino ( ( ….); $\mathrm{EF}=$ Esterco de frango (- - -); EC = Esterco caprino (-)

O esterco caprino elevou o conteúdo de $\mathrm{P}$ nas plantas para até $8,5 \mathrm{~g} \mathrm{~kg}^{-1}$ de matéria correspondente a dose estimada de 3,69\%. A ordem dos teores de fósforo entre as distintas fontes orgânicas foi: esterco de bovino>esterco de frango $>$ esterco de caprino, como registrado também por Santos (2002). Ao comparar esses resultados com os 1,7 e $4,1 \mathrm{~g} \mathrm{~kg}^{-1} \mathrm{de}$ fósforo obtidos por Costa, Haag e Sarruge (1972) em plantas com e sem deficiência nutricional se verifica que esses valores foram inferiores aos obtidos no presente trabalho.

A fonte orgânica esterco de frango inibiu a acumulação de potássio nas folhas do quiabeiro. Possivelmente esse declínio seja resultado do 
menor conteúdo de $\mathrm{K}$ no respectivo insumo como indicado na (Tabela 1). Nas demais fontes os teores do macronutriente aumentaram até 28,8 e $30,01 \mathrm{~g}$ $\mathrm{kg}^{-1}$ nas doses de 15 e 10,9\% respectivamente para o esterco bovino e caprino (Figura 3). As fontes de matéria orgânica incorporadas ao solo que promoveram os maiores teores de potássio nas folhas foram: esterco caprino seguido do esterco bovino e do esterco de frango. Essa situação diverge da ordem do nutriente na composição das fontes que é: esterco bovino>esterco caprino>esterco de frango (Tabela 1). Apesar dos teores de $\mathrm{K}$ decrescerem como o aumento das doses do esterco de frango os valores, mesmo sendo inferiores aos do esterco caprino e esterco bovino, na amplitude de 27 a $24 \mathrm{~g} \mathrm{~kg}^{-1}$ as plantas não emitiram sintomas visuais de deficiência. Comparativamente, os resultados foram superiores aos apresentados por Costa, Haag e Sarruge (1972) na matéria seca foliar de quiabeiro com valores de 10,5 e $20 \mathrm{~g} \mathrm{~kg}^{-1}$ de potássio em plantas com e sem deficiência nutricional. Resultados superiores aos 2,3 $\mathrm{g} \mathrm{k}^{-1}$ também foram registrados por Mota et al. (2008) na matéria seca dos frutos do quiabeiro sob adubação mineral.

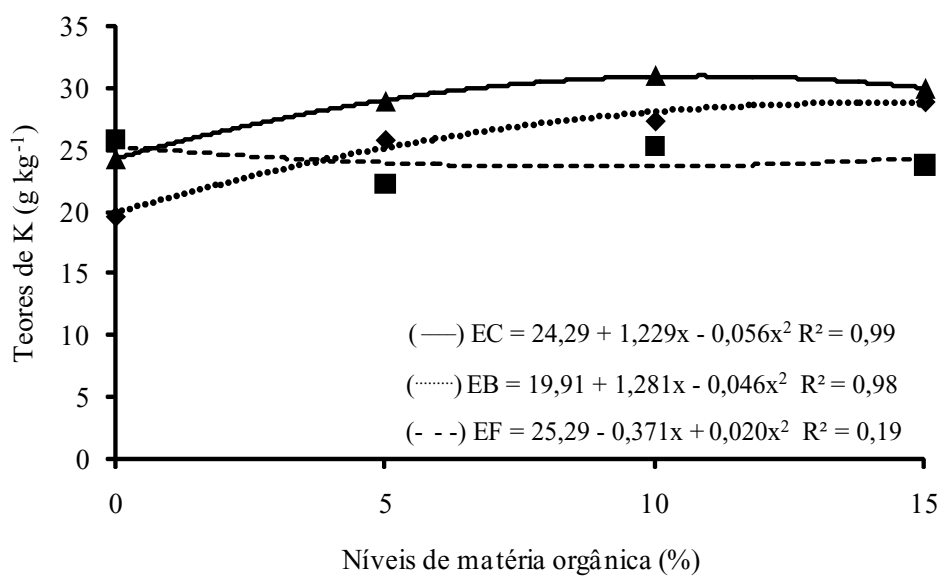

Figura 3. Teores de potássio na matéria seca das folhas do quiabeiro em função de fontes e níveis de matéria orgânica incorporadas ao solo: $\mathrm{EB}=$ esterco bovino ( $\cdots \cdots \cdots \cdot) ; \mathrm{EF}=$ esterco de frango $(---)$; EC = Esterco caprino ( - )

Dentre as fontes de matéria orgânica a única que promoveu aumento de cálcio na matéria seca foliar do quiabeiro foi o esterco de frango, com maior valor de $29,1 \mathrm{~g} \mathrm{~kg}^{-1}$ na dose máxima estimada de $5 \%$ (Figura 4). Nos tratamentos com as demais fontes a acumulação do nutriente nas folhas decresceu com o aumento das doses aplicadas. Essa situação contraria os resultados da literatura em que a adição de matéria orgânica melhora a condição física do solo e aumenta a disponibilidade de cálcio às plantas (LOPES; GUILHERME, 2007). Os valores oscilaram de 14,19 para até $30,27 \mathrm{~g} \mathrm{~kg}^{-1}$ e se situam nos limites ou até superiores às exigências da maioria das plantas hortículas (MALAVOLTA; VITTI; OLIVEIRA, 1997). A ordem dos valores médios de cálcio nas folhas das plantas referentes às fontes foi: esterco de frango>esterco caprino>esterco bovino, essa seqüência é a mesma dos teores de cálcio na composição das distintas fontes orgânicas conforme indicado na (Tabela 1). Esses valores discordam dos apresentados por Mota et al. (2008) ao estudarem a composição mineral em frutos de quatro cultivares de quiabo com teores oscilando de 5,1 à 9,3 $\mathrm{g} \mathrm{kg}^{-1}$ na matéria seca dos frutos. Costa, Haag e Sarruge (1972), obtiveram maiores valores de cálcio quando estudaram a absorção de macro e micronutrientes em folhas de quiabeiro sem e com deficiência mineral obtendo os teores de 37,3 e $29,4 \mathrm{~g} \mathrm{~kg}^{-1}$ respectivamente. 


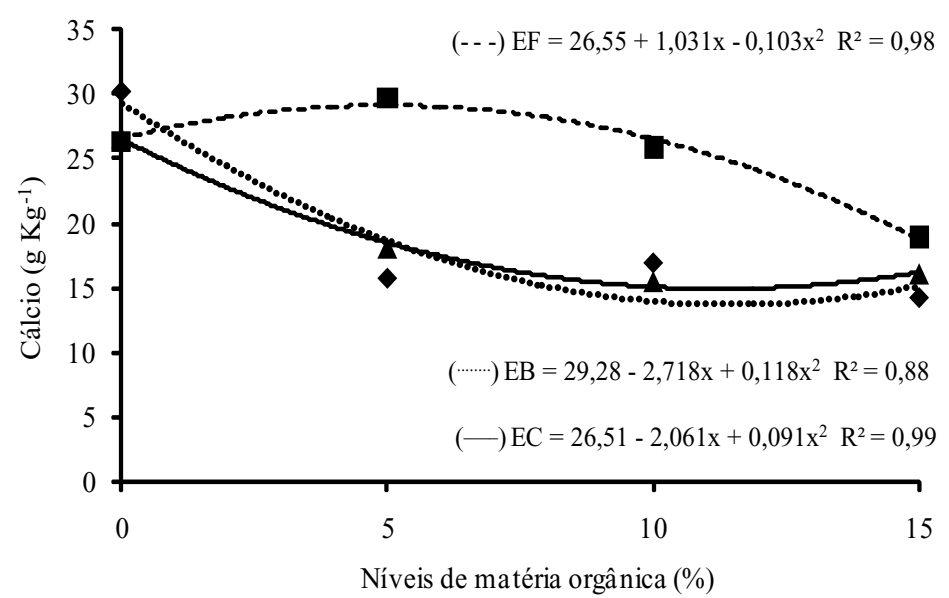

Figura 4. Teores de cálcio na matéria seca das folhas do quiabeiro em função de fontes e níveis de matéria orgânica incorporadas ao solo: $\mathrm{EB}=$ Esterco bovino ( ( …...); EF = Esterco de frango (- - -); EC = Esterco caprino (-)

Independentemente da fonte, a adição de matéria orgânica promoveu aumento no teor foliar de magnésio nas plantas até as doses máximas estimadas de $12,3 \%$ referente ao esterco de frango, $13 \%$ ao esterco bovino e $13,9 \%$ ao esterco caprino, correspondentes aos maiores teores de 15,7; 14,9 e $16,1 \mathrm{~g} \mathrm{~kg}^{-1}$ respectivamente (Figura 5). Os teores variam entre 9,62 e 16,14 $\mathrm{g} \mathrm{kg}^{-1}$ de matéria seca e são superiores aos considerados suficientes à maioria das plantas olerícolas e frutícolas (MALAVOLTA; VITTI; OLIVEIRA, 1997).
Apesar do esterco de frango conter menos magnésio que o esterco bovino (Tabela 1) a sua mineralização mais rápida pode ter contribuído para diminuição da disponibilidade do nutriente no solo, ao longo do tempo de aplicação. Outro fator pode ser o maior conteúdo de $\mathrm{N}$ no esterco de frango que acelera a mineralização, resultando em maior disponibilidade do nutriente ás plantas como observado também para o nitrogênio, fósforo e cálcio.

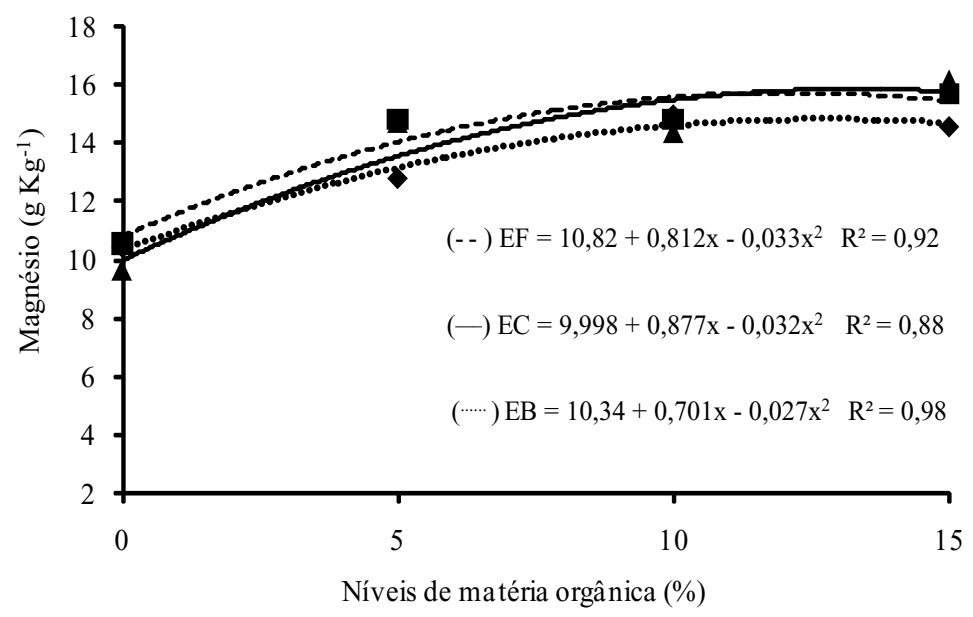

Figura 5. Teores de magnésio na matéria seca das folhas do quiabeiro em função de fontes e níveis de matéria orgânica incorporadas ao solo: $\mathrm{EB}=$ Esterco bovino ( (…..); $\mathrm{EF}=$ Esterco de frango (- - -); EC $=$ Esterco caprino (-) 


\section{Conclusão}

O esterco de frango proporcionou maiores teores foliares de cálcio, fósforo e magnésio, o esterco de caprino maior acumulação de potássio e o esterco de bovino mais nitrogênio nas folhas do quiabeiro.

Não foram obtidas doses estatisticamente mais eficientes para cada nutriente nas distintas fontes de matéria orgânica.

\section{Referências}

BERBARA, L. L. B.; FREIRE, L. R.; FERNANDES, M. S. Influência da colonização micorrízica arbuscular sobre a nutrição do quiabeiro. Pesquisa Agropecuária Brasileira, Brasília, v. 34, n. 9, p. 1645-1653, 1999.

COSTA, M. C. B.; HAAG, H. P.; SARRUGE, J. R. Nutrição mineral de hortaliças. Absorção de macro e micronutrientes pela cultura do quiabeiro (Hibiscus esculentum L.). In: REUNIÃO DA SOCIEDADE BRASILEIRA DE HORTICULTURA, 29., 1972, Piracicaba. Anais. Piracicaba: ESALQ, 1972. p. 109125.

EMPRESA BRASILEIRA DE PESQUISA AGROPECUÁRIA - EMBRAPA. Centro Nacional de Pesquisa de Solos. Manual de métodos de análise de solo. 2. ed. Rio de Janeiro: Embrapa-CNPS, 1997. 212 p.

FERREIRA, P. V. Estatística experimental aplicada à agronomia. 3. ed. Maceió: UFAL, 2000. 604 p.

FILGUEIRA, F. A. R. Novo manual de olericultura. Viçosa: UFV, 2000. 402 p.

Novo manual de olericultura: agrotecnologia moderna na produção e comercialização de hortaliças. 3 . ed. Viçosa: UFV, 2008. 421 p.

LOPES, A. S.; GUILHERME, L. R. G. Fertilidade do solo e produtividade agrícola. In: NOVAIS, R. F.; ALVAREZ, V. V. H.; BARROS, N. F.; FONTES, R. L. F.; CANTARUTTI, R. C.; NEVES, J. C. L. (Ed.). Fertilidade do Solo. Viçosa: Sociedade Brasileira de Ciência do Solo, 2007. cap. 1, p. 1-64.

MALAVOLTA, E.; VITTI, G. C.; OLIVEIRA, S. A. Avaliação do estado nutricional das plantas: princípios e aplicações. Piracicaba: POTAFOS, 1997. 201 p.
MOTA, W. F.; FINGER, F. L.; SILVA, D. J. H.; CORRÊA, P. C.; FIRME, L. P.; NEVES, L. L. M. Caracterização físico-química de frutos de quatro cultivares de quiabo. Horticultura Brasileira, Brasília, v. 23, n. 3, p. 722-725, 2005.

MOTA, W. F.; FINGER, F. L.; SILVA, D. J. H.; CORRÊA, P. C.; FIRME, L. P.; RIBEIRO, R. A. Composição mineral de frutos de quatro cultivares de quiabeiro. Ciência $e$ Agrotecnologia, Lavras, v. 32, n. 3, p. 762-767, 2008.

NAGAI, H. Quiabo Hibiscus esculentus L. In: FAHL, J. I.; CAMARGO, M. B. P.; PIZZINATTO, M. A.; BETTI, J. A.; MELO, A. M. T.; MARIA, I. C.; FURLANI, A. M. C. Instruções agrícolas para as principais culturas econômicas. 69. ed. Campinas: Instituto Agronômico de Campinas, IAC, 1998. p. 235-236. (Boletim, 2000).

OLIVEIRA, A. P.; ALVES, A. U.; DORNELAS, C. S. M.; SILVA, J. A.; PORTO, M. L.; ALVES, A. U. Rendimento de quiabo em função de doses de nitrogênio. Acta Scientiarum. Agronomy, Maringá, v. 25, n. 2, p. 265-268, 2003.

OLIVEIRA, A. P.; DORNELAS, C. S. M.; ALVES, A. U.; ALVES, A. U.; SILVA, J. A.; OLIVEIRA, A. N. P. Reposta do quiabeiro às doses de fósforo aplicadas em solo arenoso. Horticultura Brasileira, Brasília, v. 25, n. 2, p. 180-183. 2007b.

OLIVEIRA, R. D. L.; SILVA, M. B.; AGUIAR, N. D. C.; BÉRGAMO, F. L. K.; COSTA, A. S. V; PREZOTTI, L. Nematofauna associada à cultura do quiabo na região leste de Minas Gerais. Horticultura Brasileira, v. 25, n. 1, p. 88-93. 2007a.

PIRES, A. A.; MONNERAT, H. P.; MARCIANO, C. R.; PINHO, L. G. R.; ZAMPIROLLI, P. D.; ROSA, R. C.; MUNIZ, R. A. Efeito da adubação alternativa do maracujazeiro amarelo nas características químicas e físicas do solo. Revista Brasileira de Ciência do Solo, Viçosa, v. 32, n. 5, p. 1997-2005, 2008.

RODOLFO JÚNIOR, F.; CAVALCANTE, L. F.; BURITI, E. S. Crescimento e produção do maracujazeiro amarelo em solo com biofertilizantes e adubação mineral com NPK. Caatinga, Mossoró, v. 21, n. 5, p. 134-145, 2008. Edição Especial.

SANTOS, E. D. P. Comportamento vegetativo $e$ nutricional da pinheira submetida a diferentes níveis de água e tipos de cobertura morta do solo. 2001. Trabalho de Conclusão de Curso (Graduação em Agronomia) Centro de Ciências Agrárias, Universidade Federal da Paraíba, Areia. 
SANTOS, L.C.F. Desenvolvimento vegetativo eprodutivo do quiabeiro sob fontes e doses de matéria orgânica. 2002. Trabalho de Conclusão de Curso (Graduação em Agronomia) - Centro de Ciências Agrárias, Universidade Federal da Paraíba, Areia.

SANTOS, L. F.; CAVALCANTE, L. F.; DINIZ, A. A.; CURVELO, C. R. S.; CAVALCANTE, I. H. L.; SOUSA, G. G. Crescimento vegetativo e produtivo do quiabeiro sob fontes e doses de matéria orgânica. In: SIMPÓSIO DO CPG EM MANEJO DE SOLO E ÁGUA, 27., 2005, Areia. Anais... Areia: UFPB, p. 40-52, 2005.
SANTOS. H. G.; JACOMINE, P. K. T.; ANJOS, L. H. C.; OLIVEIRA, J. B.; COELHO, M. R.; LUMBRERAS, J. F.; CUNHA, T. J. F. Sistema brasileiro de classificação de solos. 2. ed. Rio de Janeiro: Embrapa Solos, 2006. $306 \mathrm{p}$.

YU-KUI, R.; SHI-LING, J.; FU-SUO, Z.; JIAN-BO, S. Effects of nitrogen fertilizer input on the composition of mineral elements in corn grain. Agrociência, México, v. 43, n. 1, p. 21-27, 2009. 
